\title{
Patterns of Systolic Blood Pressure Control in the United States, 2016
}

Shreya J. Shah, $M D^{1,2}$ and Randall S. Stafford, $M D, P h D^{7}$

'Department of Medicine, Stanford University, Palo Alto, CA, USA; ${ }^{2}$, Stanford, USA.

KEY WORDS: blood pressure; hypertension; epidemiology; primary care; internal medicine.

J Gen Intern Med 33(8):1224-6

DOI: $10.1007 / \mathrm{s} 11606-018-4452-4$

(c) Society of General Internal Medicine 2018

\section{INTRODUCTION}

Hypertension affects over 100 million individuals in the USA and is a major risk factor for cardiovascular disease (CVD). ${ }^{1}$ Treatment to reduce blood pressure (BP) reduces the risk of CVD, stroke, heart failure, chronic kidney disease, and all-cause mortality. Despite these benefits, the detection, treatment, and control of hypertension remain suboptimal. Treatment efforts need to be monitored because of their impact on public health.

The standards for evaluating BP control have shifted over the past decade. JNC 7 targeted systolic blood pressure $(\mathrm{SBP})<140 \mathrm{mmHg}$ for most and $<130$ in higher risk patients. ${ }^{2}$ In contrast, JNC 8 relaxed treatment targets to $<150$ in most older patients (age $\geq 60$ ) and SBP $<140$ for all others. ${ }^{3}$ Increasing evidence, particularly from SPRINT, suggests the feasibility and benefits of intensive BP control goals well below $<140$ / $90 .{ }^{4}$ Recent AHA/ACC guideline targets $130 / 80$ for a broad range of patients with elevated risk of CVD events. ${ }^{1}$

Racial/ethnic disparities in hypertension management persist. NHANES data shows the highest prevalence of hypertension among blacks as well as less adequate BP control among blacks and Hispanics. Lower socioeconomic status, independent of race/ethnicity, is correlated with higher prevalence of hypertension and CVD. ${ }^{1}$

We analyzed current national patterns of BP management using a variety of potential SBP targets to assess overall levels of BP control as well as disparities in treatment.

\section{METHODS}

We identified patients treated for hypertension in 2016 using the National Drug and Therapeutic Index (NDTI) from IQVIA (formerly IMS Health), Plymouth Meeting
PA, a nationally representative survey of 4158 officebased physicians. Participating physicians reported information on the drug therapies used for specific diagnoses as well as information on patient clinical and demographic characteristics.

We used ICD-9 codes 401.0-401.9 to select patients with a diagnosis of hypertension. We extracted data on SBP and other patient characteristics. To compare SBP among these different groups, we calculated proportions based on each subgroup (i.e., males with SBP $<140$ divided by the total number of males reported to have treated hypertension). Ninety-five percent confidence intervals (CIs) were calculated using IQVIA tables of relative standard errors that accounted for the complex, multistage NDTI sampling design. $p$ values were calculated using a 2-tailed $t$ test.

\section{RESULTS}

There were a total of 70 million visits for patients treated with medications for a diagnosis of hypertension in 2016. Among this group, BP control varied substantially. In total, $42.4 \%$ of patients had SBP $\geq 140$ and $24.4 \%$ of patients had SBP $\geq 150$ (Table 1 and Fig. 1).

There were higher rates of SBP $\geq 140$, SBP $\geq 150$, and SBP $>160$ among blacks and Hispanics vs. whites and Asians ( $p$ values $<0.001$ for all). There were also higher rates of $\mathrm{SBP} \geq 140, \mathrm{SBP} \geq 150$, and $\mathrm{SBP} \geq 160$ among those with Medicaid compared to those with Medicare, third party and HMO insurance ( $p$ values < 0.001 for all). SBP control did not vary by gender or age (Table 1).

\section{DISCUSSION}

Among patients accessing outpatient care and prescribed treatment for hypertension, a substantial portion continue to have elevated BP. Many patients have inadequately controlled $(\geq 140)$ or poorly controlled $(\geq 150)$ SBP, based on previous JNC guidelines. These shortfalls become even more prominent at lower treatment targets that reflect the benefits of intensive treatment observed in SPRINT and incorporated into the AHA/ACC guidelines.

Published online April 20, 2018 
Table 1 Systolic Blood Pressure Control by Patient Demographics

\begin{tabular}{|c|c|c|c|c|c|c|c|c|}
\hline & $\begin{array}{l}\text { SBP }<120 \\
(\%)\end{array}$ & $\begin{array}{l}\text { SBP 120-129 } \\
(\%)\end{array}$ & $\begin{array}{l}\text { SBP 130-139 } \\
(\%)\end{array}$ & $\begin{array}{l}\text { SBP 140-149 } \\
(\%)\end{array}$ & $\begin{array}{l}\text { SBP 150-159 } \\
(\%)\end{array}$ & $\begin{array}{l}\mathrm{SBP} \geq 140 \\
(\%)\end{array}$ & $\begin{array}{l}\mathrm{SBP} \geq 150 \\
(\%)\end{array}$ & $\begin{array}{l}\mathrm{SBP} \geq 160 \\
(\%)\end{array}$ \\
\hline \multicolumn{9}{|l|}{ Age } \\
\hline Age $\geq 60$ & 13.0 & 21.8 & 25.5 & 18.1 & 8.5 & 39.7 & 21.7 & 13.2 \\
\hline Age $<60$ & 10.6 & 18.5 & 25.6 & 18.3 & 10.8 & 45.4 & 27.1 & 16.3 \\
\hline \multicolumn{9}{|l|}{ Gender } \\
\hline Male & 10.4 & 18.0 & 26.6 & 19.1 & 10.1 & 45.0 & 25.9 & 15.8 \\
\hline Female & 13.6 & 22.9 & 24.2 & 16.8 & 8.5 & 39.3 & 22.5 & 14.0 \\
\hline \multicolumn{9}{|c|}{ Race/ethnicity } \\
\hline White & 12.9 & 21.5 & 26.3 & 17.3 & 8.7 & 39.2 & 21.9 & 13.3 \\
\hline Black & 7.9 & 17.0 & 25.4 & 19.7 & 11.4 & 49.8 & 30.1 & 18.7 \\
\hline Hispanic & 11.0 & 18.8 & 19.9 & 21.3 & 11.6 & 50.3 & 29.0 & 17.5 \\
\hline Asian & 14.0 & 18.7 & 24.4 & 19.3 & 11.3 & 42.8 & 23.6 & 12.3 \\
\hline Other & 14.1 & 21.0 & 20.9 & 22.0 & 7.6 & 44.0 & 22.0 & 14.3 \\
\hline \multicolumn{9}{|c|}{ Insurance type } \\
\hline $\mathrm{HMO}$ & 12.0 & 22.3 & 26.6 & 19.1 & 8.2 & 39.1 & 20.0 & 11.8 \\
\hline Medicare & 13.3 & 21.6 & 26.0 & 17.3 & 8.7 & 39.1 & 21.8 & 13.1 \\
\hline 3rd party & 11.7 & 19.9 & 26.2 & 18.6 & 9.1 & 42.2 & 23.6 & 14.5 \\
\hline Medicaid & 8.7 & 12.3 & 18.2 & 19.7 & 15.1 & 60.8 & 41.0 & 25.9 \\
\hline Other* & 7.8 & 17.0 & 24.0 & 15.0 & 15.0 & 51.3 & 36.3 & 21.3 \\
\hline Total & 11.9 & 20.3 & 25.4 & 18.0 & 9.4 & 42.4 & 24.4 & 15.0 \\
\hline
\end{tabular}

Source: IQVIA, NDTI, 2016

*Other includes unknown and no insurance

Blacks, Hispanics, and patients with Medicaid had notably poorer BP control. Consistent with prior studies, these findings indicate that treatment disparities persist even among patients with access to health care. These disparities translate into excess preventable adverse outcomes in these groups.

While our analysis could not measure patient affordability or adherence to medications, our patient sample had access to primary care and was prescribed antihypertensive medications. Our results, therefore, indicate that multiple issues other than health care access continue to impact health disparities in CVD outcomes.
Even when utilizing relaxed treatment targets, a significant proportion of patients have poorly controlled SBP, with larger shortfalls in BP control present for more intensive treatment goals. This demonstrates a failure of the current system of care and indicates a pressing need for interventions to improve both BP management and alleviate health disparities. This will require investment in strategies beyond physicians' office visits with greater application of multidisciplinary approaches in a variety of clinical and non-clinical settings.

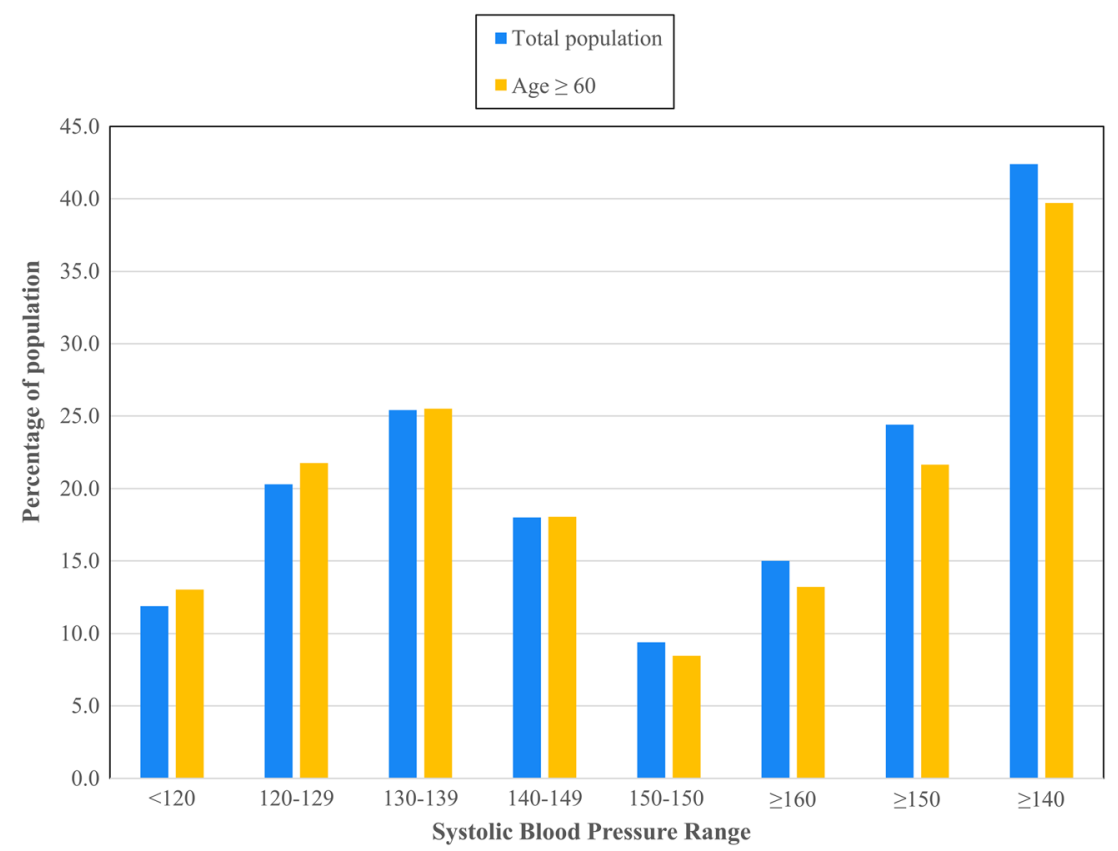

Figure 1 Systolic blood pressure control among total population as well as among those age $\geq 6$. 
Funding and Data Sources: Dr. Stafford was supported by a midcareer mentoring award (NIH K24 HLO86703) and serves as an unpaid member of an IQVIA scientific advisory committee.

Corresponding Author: Shreya J. Shah, MD; , Stanford, USA

\section{Compliance with Ethical Standards:}

Conflict of Interest: The authors declare that they do not have a conflict of interest.

\section{REFERENCES}

1. Whelton PK, Carey RM, Aronow WS, Casey DE, Collins KJ, Himmelfarb CD, DePalma SM, Gidding S, Jamerson KA, Jones DW, MacLaughlin EJ, Muntner P, Ovbiagele B, Smith SC, Spencer CC, Stafford RS, Taler SJ, Thomas RJ, Williams KA, Williamson JD, Wright JT. 2017 ACC/
AHA/AAPA/ABC/ACPM/AGS/APhA/ASH/ASPC/NMA/PCNA Guideline for the Prevention, Detection, Evaluation, and Management of High Blood Pressure in Adults. Hypertension. 2017;HYP.0000000000000065. Originally published November 13, 2017

2. Chobanian AV, Bakris GL, Black HR, Cushman WC, Green LA, Izzo JL Jr., Jones DW, Materson BJ, Oparil S, Wright JT Jr., Roccella EJ; National Heart, Lung, and Blood Institute Joint National Committee on Prevention, Detection, Evaluation, and Treatment of High Blood Pressure; National High Blood Pressure Education Program Coordinating Committee. The Seventh Report of the Joint National Committee on Prevention, Detection, Evaluation, and Treatment of High Blood Pressure: the JNC 7 report. JAMA 2003;289:2560-2572.

3. James PA, Oparil S, Carter BL, et al. 2014 evidence-based guideline for the management of high blood pressure in adults: report from the panel members appointed to the Eighth Joint National Committee (JNC 8). JAMA 2014;311(5):507-20.

4. Wright JT, Williamson JD, Whelton PK, et al. A randomized trial of intensive versus standard blood-pressure control. N Engl J Med 2015;373(22):2103-16. 